\title{
Low Voltage FESEM of Geological Materials
}

\author{
Chi Ma and George R. Rossman
}

Division of Geological and Planetary Sciences, California Institute of Technology, Pasadena, CA 91125

Low voltage FESEM (i.e., operated at several hundred volts to $5 \mathrm{kV}$ ) which offers advantages in surface imaging due to reduced beam penetration ${ }^{1}$, was found to be particularly useful in the investigation of uncoated, fine geological materials down to nano-scale. Here are three examples to highlight projects being conducted in our FESEM facility.

Kaolinite is one of the most important industrial minerals. Information about its surface properties and cation exchange capacity are important in both ore processing and applications of the clay mineral ${ }^{2}$. Low voltage SE imaging (Fig. 1) reveals detailed (001) surface features of kaolinite, which is not obtainable with high voltage SEM and TEM. Kaolinite is very beam sensitive and can be damaged in several seconds under the TEM beam. However, microtome TEM samples may be easily examined under LV SEM to show thickness perpendicular to (001) and cross section features. Such information allows easy access to direct surface area determination of clay minerals.

Rainbow hematite displays a spectrum of beautiful colors. A thin film of an aluminum phosphate was found to coat this hematite. The thin films with an index of refraction which differs from hematite are believed to cause the color ${ }^{3}$. Our LV FESEM imaging (Fig. 2) shows that the thin film consists of nano-crystals arranged in three directions $\left(120^{\circ}\right.$ apart $)$. The rod-shaped crystals have a diameter from 15 to $35 \mathrm{~nm}$. We now need to determine how these nano-crystals might contribute to the cause of the colors. The LV FESEM contributes an exciting new dimension to this problem that simply could not be observed under conventional SEM.

Non-crystalline opals in hydrothermal altered ignimbrite from Lake Tecopa, California, and an Australian gem quality opal, are being studied with LV FESEM. Although it is well known that opal consists of silica spheres, LV SE imaging presents more surface information on these spheres. Silica spheres are devoid of surface features when formed in a void where they sit loosely (Fig. 3a). When voids filled with spheres or minerals like feldspar are completely replaced by silica spheres, the spheres are closely-packed. Contact features on the close-packed silica spheres (Fig. 3b) indicate that the spheres are weakly cemented. In the gem-quality opal, the spheres are tightly packed and strongly cemented (Fig. 3c) where the fracture surface breaks through the spheres. With the help of LV SEM we are trying to understand how natural opal formed and how it becomes packed.

The Caltech Geology FESEM facility is supported in part by the MRSEC Program of the NSF under DMR-0080065. The projects are funded by the White Rose Foundation and the NSF.

References

[1] C.J. Joy and D.E. Newbury, Microsc. Microanal. 7 (suppl. 2) (2001) 762.

[2] C. Ma and R.A. Eggleton, Clays and Clay Minerals, 47 (1999), 174-180.

[3] G.R. Rossman, http://minerals.gps.caltech.edu/ (2003) 


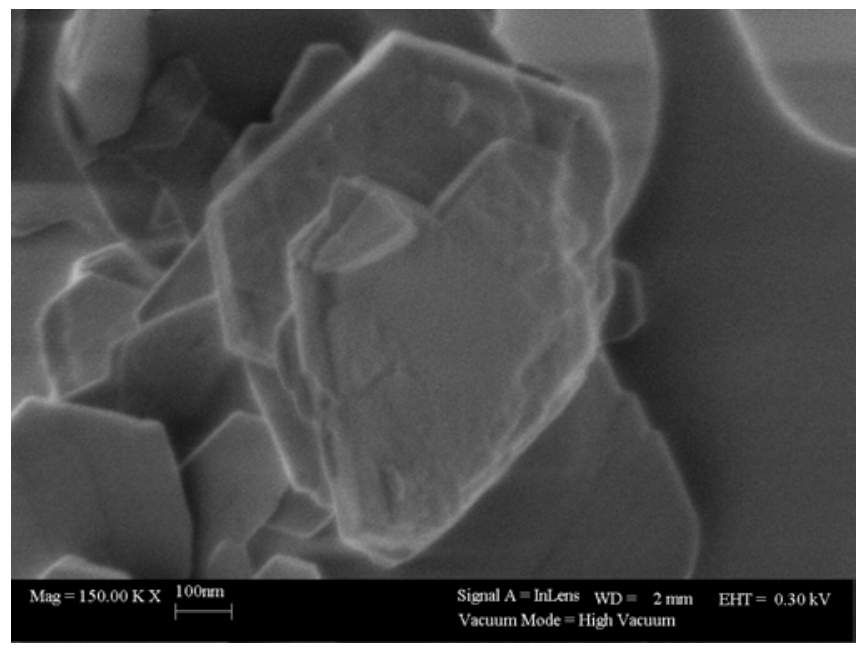

FIG. 1. Low voltage SE image revealing (001) surface features of kaolinite plates.

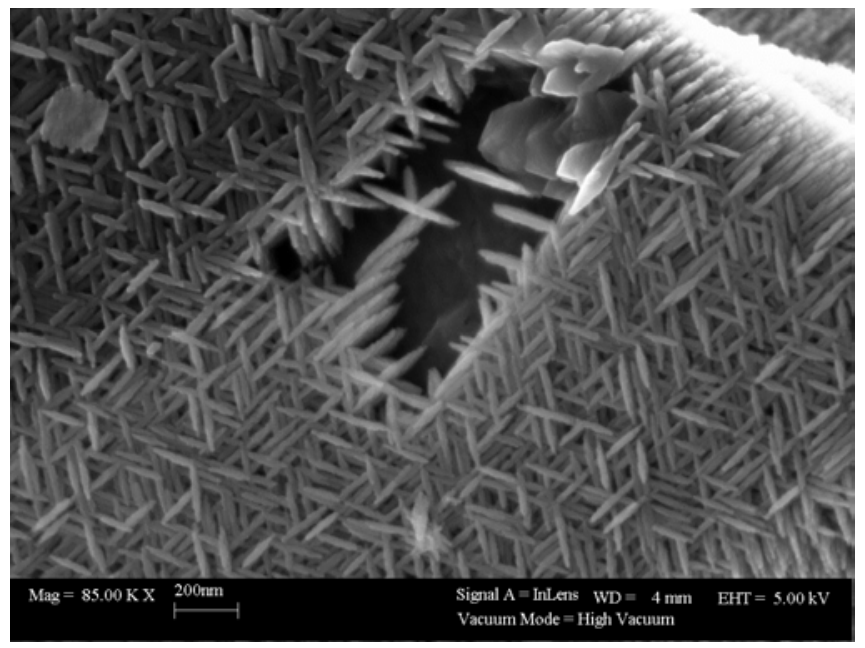

FIG. 2. Nano-crystals on the surface of rainbow hematite.

(a)

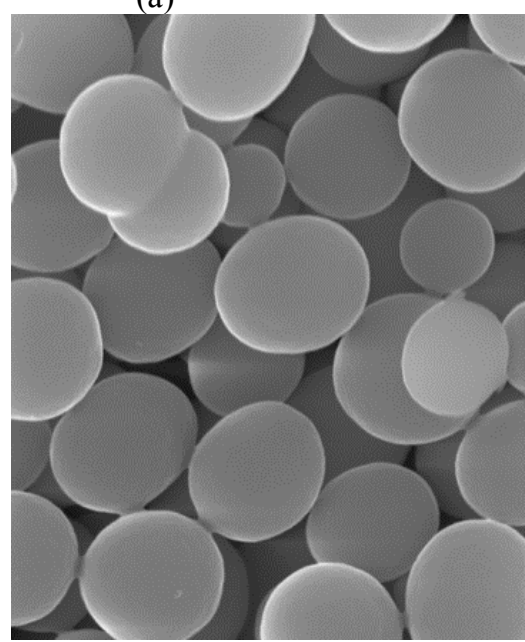

(b)

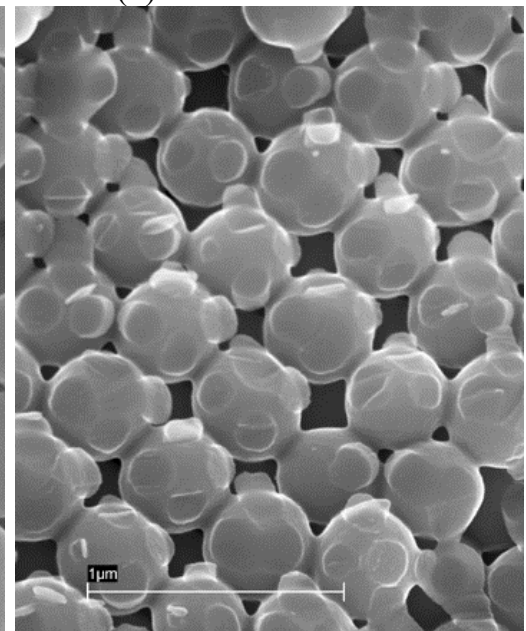

(c)

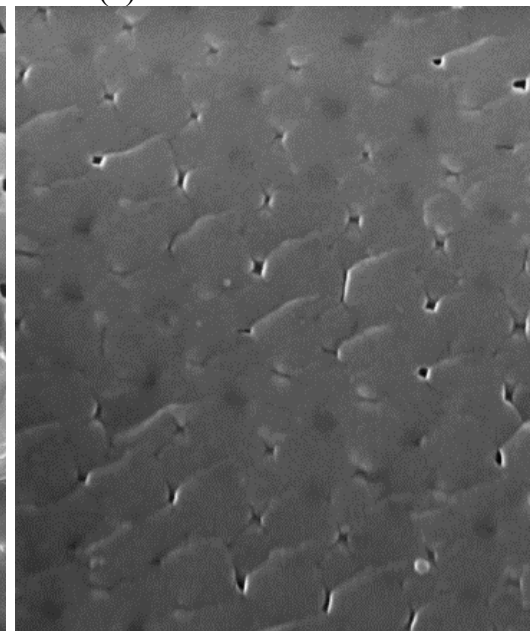

FIG. 3. SE images of opal showing (a) silica spheres formed in a void, (b) closely-packed spheres, and (c) tightly-packed silica spheres of a gem quality opal. 